\title{
Relatório com modificação de opinião: risco para o auditor?
}

Modified audit opinion: is it a risk to auditor?

Informe de auditoría con opinión modificada: riesgo para el auditor?

\section{José Alves Dantas}

Doutor em Ciências Contábeis pela Universidade de Brasília (UnB)

Professor da Universidade de Brasília (UnB)

Endereço: Campus Darcy Ribeiro - Prédio da FACE - Asa Norte

CEP: 70910-900 - Brasília/DF - Brasil

E-mail: josealvesdantas@unb.br

Telefone: (61) 98406.9524

\section{Igor Theodoroviz Barreto}

Bacharel em Ciências Contábeis pela Universidade de Brasília (UnB)

Endereço: SQS 310, Bloco K, Apto 508 - Asa Sul

CEP: 70363-110 - Brasília/DF - Brasil

E-mail: igortbarreto@gmail.com

Telefone: (61) 99822.3826

\section{Paulo Roberto Matos de Carvalho}

Bacharel em Ciências Contábeis pela Universidade de Brasília (UnB)

Quadra 4, Lote 1, Condomínio Residencial Galileia, Recanto das Emas

CEP: 72669-230 - Brasília/DF - Brasil

E-mail: pauloja@msn.com

Telefone: (61) 992433917

Artigo recebido em 13/12/2016. Revisado por pares em 16/02/2017. Reformulado em 24/06/2017. Recomendado para publicação em 22/09/2017 por Carlos Eduardo Facin Lavarda (Editor-Chefe). Publicado em 31/12/2017. 


\section{Resumo}

Este estudo teve por objetivo avaliar se a emissão de relatório de auditoria com opinião modificada impacta a sequência do contrato entre auditor e cliente, bem como se o fato da firma de auditoria ser uma big four ou a empresa auditada adotar práticas de governança corporativa reduz o risco de descontinuidade da relação contratual, mesmo com a emissão de opinião modificada. Testes empíricos realizados com base nos relatórios de auditoria, de 2009 a 2015, de 338 empresas listadas na BM\&FBovespa revelaram que no âmbito do mercado de capitais brasileiro: há relação positiva entre a opinião modificada e a troca do auditor no período seguinte; e o fato da firma de auditoria ser uma big four ou a empresa cliente pertencer aos segmentos de governança corporativa do mercado não reduzem esse risco de descontinuidade contratual entre as partes, nos casos de emissão de opinião modificada.

Palavras chave: Auditoria; Relatório de auditoria; Demissão do auditor; Opinião Modificada

\section{Abstract}

This paper aimed to evaluate whether the audit report issued with modified opinion impacts the agreement between auditor and client. In addition, it was found whether the fact that once the audit firm is a big four or the audited company adopts corporate governance practices can reduce the risk of discontinuation of the contractual relationship, even with the issue of modified opinion. The empirical tests revealed that: in the brazilian capital market, there is a positive and statistically significant relationship between the modified opinion and the auditors' changing in the following period; and the fact of an audit firm being a big four or the company adopts corporate governance practices do not reduce the risk of discontinuity between the parts. The results demonstrate a worrying picture concerning auditors' independency when they issued a report with modified opinion.

Keywords: Audit; Audit report; Auditor's dismissal; Modified opinion

\section{Resumen}

Este estudio tuvo como objetivo evaluar si la emisión de un informe de auditoría con opinión modificada afecta la secuencia de un acuerdo entre el auditor y el cliente, así como si el hecho de que la firma de auditoría sea una big four o la empresa auditada adopte prácticas de gobernanza corporativa reduzca el riesgo de interrupción de la relación contractual, incluso con la emisión de opinión modificada. Pruebas empíricas realizadas en base a los informes de auditoría, de 2009 a 2015, de 338 empresas listadas en la BM\&FBovespa revelaron que en el mercado de capitales brasileño: existe una relación positiva entre la opinión modificada y el cambio de auditor en el periodo siguiente; y el hecho de que la firma de auditoría sea una big four o la empresa cliente pertenezca a los segmentos de la gobernanza corporativa del mercado no reducen el riesgo de discontinuidad contractual entre las partes, en los casos de emisión de opinión modificada.

Palabras clave: Auditoría; Informe de auditoría; Renuncia del auditor; Opinión modificada

\section{Introdução}

De acordo com o Conceptual Framework for Financial Reporting do International Accounting Standards Board [IASB] (2015), a utilidade da informação contábil está associada ao atendimento de características qualitativas fundamentais - relevância e representação fidedigna - e de melhorias - comparabilidade, verificabilidade, tempestividade e compreensibilidade. No mesmo sentido, Dantas et. al. (2011) afirmam que a qualidade do processo de divulgação financeira está relacionada com a disponibilidade de uma informação 
contábil eficiente e confiável, que reduza a assimetria informacional entre a administração da entidade divulgadora e os usuários das demonstrações financeiras.

Nesse contexto, assume particular importância o papel desempenhado pelos auditores independentes, profissionais responsáveis por revisar as demonstrações financeiras e opinar sobre se foram elaboradas de acordo com o modelo contábil de referência e se estão livres de distorções materiais. Assim, a auditoria é vista como um instrumento primordial para o funcionamento dos mercados de capitais, tendo a missão de agregar confiabilidade e credibilidade às informações financeiras - condição para que os agentes de mercado possam tomar decisões com suporte informacional adequado.

A ação dos auditores se justifica, principalmente, pelos potenciais interesses que a administração da entidade divulgadora possa ter no sentido de manipular as informações financeiras e obter benefícios em relação aos usuários. É o caso, por exemplo, da prática de gerenciamento de resultados, caracterizado pelo julgamento arbitrário que os gerentes fazem sobre as informações financeiras a fim de alterar a percepção do usuário sobre o desempenho econômico-financeiro da empresa (NIYAMA; RODRIGUES; RODRIGUES, 2015). Ainda segundo os autores, esse gerenciamento ocorre devido a diversos fatores, como, incentivos contratuais, incentivo de fins tributários e fatores tanto externos quanto internos que visam atender expectativas de usuários.

Para que possa cumprir apropriadamente essa missão de mitigar possibilidades de fraudes e manipulação de informações contábeis, a Securities and Exchange Commission [SEC] (2000) estabelece que a independência da firma de auditoria é essencial para minimizar a interferência externa no julgamento do auditor. Como, no entanto, a empresa auditada é quem contrata e remunera os serviços de auditoria, isso acaba por gerar questionamentos sobre se essa relação não afetaria a independência de atuação dos auditores, uma vez que a administração da empresa não ficaria satisfeita em receber uma opinião contrária aos seus interesses.

Não por acaso, em boa parte dos escândalos corporativos ocorridos ao longo da história do mercado de capitais - como o clássico caso Enron, por exemplo, que resultou na descontinuidade da Arthur Andersen, uma das maiores firmas de auditoria à época - há questionamentos sobre a atuação dos auditores. No Brasil, podem ser citados como exemplos de questionamentos sobre a atuação dos auditores os casos do Banco Nacional, do Banco Santos, da Sadia, e mais recentemente da Petrobras, que geraram questionamentos sobre a pertinência do processo de auditoria e a integridade dos profissionais responsáveis por essa atividade.

A esse respeito, Hennes, Leone e Miller (2013) ressaltam que o prévio conhecimento de que uma opinião modificada (relatório com ressalvas, com opinião adversa ou com abstenção de opinião) gera altos custos para o cliente, desde pagamentos de honorários extras para auditoria verificar de maneira mais aprofundada os problemas identificados, até o custo de oportunidade do investidor, que ao ver um relatório com ressalva decide por migrar o seu investimento para outra companhia.

Tendo em vista esse contexto, o presente estudo tem por propósito avaliar se a emissão de um relatório de auditoria com opinião modificada impacta a sequência do contrato entre auditor e cliente, ou seja, se a emissão de opinião contrária aos interesses da administração coloca em risco a continuidade do contrato de prestação de serviços entre as partes. É verificado, também, se essa relação é afetada pelo fato da firma de auditoria ser uma big four ou a companhia auditada adotar práticas de governança corporativa reconhecidas no mercado. Adicionalmente, a fim de evitar distorções nos resultados, será avaliado se a troca de auditoria pode estar vinculada com o rodízio obrigatório de auditoria. Para esse fim serão examinados relatórios de auditoria sobre as demonstrações contábeis anuais das companhias abertas não 
financeiras listadas na Bolsa de Valores, Mercadorias e Futuros de São Paulo [BM\&FBovespa], considerando o período do ano de 2009 a 2015.

Nas seções seguintes, o estudo contempla: o referencial teórico usado como base para o desenvolvimento das hipóteses de pesquisa e que auxilia no entendimento de algumas questões fundamentais para o assunto (Seção 2); a apresentação dos procedimentos metodológicos utilizados para a realização dos testes empíricos (Seção 3); a apuração e a análise dos resultados (Seção 4); e as considerações finais, cotejando os resultados empíricos com os fundamentos teóricos (Seção 5).

\section{Referencial Teórico}

\subsection{O Papel da Auditoria}

Com o desenvolvimento econômico dos países e dos mercados de capitais, e a consequente expansão das empresas, questões administrativas e financeiras ainda mais complexas surgiram, tanto para as empresas como para os investidores. Com isso, os participantes dos mercados de capitais passam a demandar, cada vez mais, informações financeiras confiáveis, uma vez que administração e investidores podem apresentar objetivos distintos. Nesse contexto, destaca-se o papel da auditoria.

$\mathrm{Na}$ literatura a respeito do propósito da auditoria tem prevalecido o posicionamento da American Accounting Association [AAA], que define a auditoria como um processo sistemático de obtenção e avaliação objetiva de evidências sobre afirmações a respeito de ações e eventos econômicos (AAA, 1972). Nesse sentido, a auditoria atende aos interesses das partes envolvidas nos negócios desenvolvidos no mercado de capitais, visto que essa se caracteriza pela apresentação de uma opinião a respeito das demonstrações financeiras das empresas sobre se essas estão livres de distorções materiais e se foram elaboradas de acordo com seu respectivo referencial - os padrões contábeis pré-estabelecidos pelos órgãos reguladores, conforme destaca o Basel Committee on Banking Supervision [BCBS] (2002).

Ainda a esse respeito, Woods et. al. (2009) afirmam que o papel do auditor é afirmar, de maneira imparcial e independente, se as demonstrações financeiras apresentadas pela empresa representam uma visão justa (fair view) da situação econômico financeira da companhia.

No Brasil, a Norma Brasileira de Contabilidade de Auditoria Independente de Informação Contábil Histórica 200 [NBC TA 200] trata dos princípios e responsabilidades gerais que coordenam a execução do trabalho de auditoria. De acordo com Longo (2011), essa norma parte do princípio de que a auditoria, seguida da opinião do auditor, aumenta o grau de confiabilidade dos usuários da informação contábil. O autor afirma que os requisitos aplicáveis da NBC TA 200 são as exigências éticas, o ceticismo profissional, o julgamento profissional, evidência de auditoria apropriada e suficiente, os riscos inseridos no processo (auditoria, inerente, controle e de detecção) e, por fim, as limitações ao processo de auditoria.

Destacam-se desses requisitos, no contexto do presente estudo, as exigências que consistem na postura íntegra e ética do auditor em relação ao serviço prestado. São elas: o ceticismo, que consiste em ter uma postura sempre questionadora e alerta para evidências que possam comprometer a confiabilidade de uma informação ou documento; e o risco de auditoria, que é o risco do auditor emitir uma opinião equivocada em função dos riscos de distorção relevante e de detecção.

Cabe ainda ressaltar a limitação inerente ao processo de auditoria, uma vez que essa proporciona um nível elevado de segurança, mas não absoluto, tendo em vista que uma fraude pode envolver um esquema complexo, não identificável pelo auditor, mesmo com a aplicação 
das técnicas e procedimentos de auditoria recomendáveis. Logo, é necessário fazer uma distinção quando se fala sobre o papel do auditor. Hassink et. al. (2009), afirmam que existem gaps nas expectativas criadas pela sociedade em relação ao papel o auditor. A responsabilidade e a função do auditor dizem respeito à emissão do relatório de auditoria que contém uma opinião profissional sobre a qualidade das informações contábeis, com o intuito de proteger os usuários das informações contábeis de possíveis assimetrias da informação.

A delimitação das responsabilidades dos auditores se depreende mais apropriadamente das afirmações de Watts e Zimmerman (1986) e de Santos e Grateron (2003), que citam os possíveis conflitos da teoria de agência (assimetria da informação) e a importância do papel do auditor como ferramenta de monitoramento. Para esses autores, a auditoria ajuda a reduzir essa assimetria, assegurando a confiabilidade das demonstrações e, consequentemente, protegendo os usuários da informação contábil de distorções materiais que possam vir a prejudicar a tomada de decisão.

\subsection{Relação Auditor-Cliente}

A relação entre o auditor e o cliente se dá de maneira formal e por meio de um contrato de prestação de serviços. A intenção da empresa ao contratar esse serviço, além de cumprir exigências regulamentares, é criar condições para atrair investidores, ao atribuir grau de confiabilidade às suas demonstrações financeiras e aumentar o nível de percepção de transparência de suas informações.

A relação entre essas partes é muitas vezes de difícil entendimento. Murcia, Borba e Schiehll (2008) destacam que vários estudos demonstram que uma cobrança excessiva sobre o board da empresa, com o intuito de garantir o cumprimento das metas de resultados, pode resultar em pressão sobre o auditor e gerar um ambiente conturbado e até mesmo propício para fraudes. Zagonov (2011), por sua vez, salienta que, à medida que os auditores exercem o seu papel, assegurando a confiabilidade das demonstrações financeiras e ajudando a solucionar o conflito principal-agente da teoria de agência, aumentam também as preocupações sobre a influência da administração no trabalho de auditoria, questionando-se a sua independência e objetividade.

A respeito da relação auditor-cliente e dessa pressão que pode ser desencadeada no ambiente de trabalho, Hennes, Leone e Miller (2008) destacam que a emissão de uma opinião modificada - com ressalva(s), abstenção de opinião ou opinião adversa - pode gerar a demissão do auditor devido a: os diretores da empresa acreditarem que a equipe de auditoria deveria ter encontrado tal erro ou distorção contábil a tempo de ser corrigida; ou por reprovação do board da companhia em relação a esse relatório com opinião modificada, visto que a diretoria esperava um relatório "limpo" e que a distorção ou possível fraude não fosse apontada e/ou descoberta.

Há ainda que se ressaltar a questão de mercado e financeira que permeia essa relação contratual. Nelson, Elliot e Tarpley (2002) abordam a questão da competitividade do mercado, ressaltando o interesse da firma de auditoria em ampliar a carteira de clientes, o que pode vir a comprometer a independência profissional. DeAngelo (1981) e Larcker e Richardson (2004), vão além da competitividade e discorrem a respeito do faturamento, esses autores afirmam que em casos de um cliente responder por parte considerável dos ganhos das firmas de auditoria, o auditor pode ter sua independência afetada uma vez que esses podem visar preservar o faturamento da firma.

Todo esse cenário de pressão por resultados, competitividade e interesses da administração e de investidores, junto com os escândalos citados anteriormente desencadearam uma série de medidas, entre elas a Lei Sarbanes-Oxley. Essa Lei buscou reduzir/evitar novas fraudes e a assimetria de informação com a imposição de medidas para as empresas de capital 
aberto, como a implantação de mecanismos referentes à governança corporativa. A padronização das normas contábeis, segundo Niyama e Silva (2013), pode, também, reduzir o risco de fraudes, apesar de essa não ser a finalidade da padronização. Essas medidas podem ser compreendidas como mudanças que buscaram dar mais credibilidade à informação contábil e ao trabalho do auditor, passando maior confiança aos investidores, a partir do aumento da independência do auditor e da exigência de adoção de critérios antifraudes.

Os órgãos normatizadores, como o IASB e o Financial Accounting Standarsds Board [FASB] emitiem normas e pronunciamentos a fim de aumentar a confiabilidade das informações financeiras divulgadas pelas empresas. As normas emitidas por esses órgãos são implantadas e fiscalizadas pelos órgãos reguladores como a Comissão de Valores Mobiliários [CVM] e a SEC, por exemplo, que visam assegurar a qualidade da informação contábil, protegendo os usuários dessa informação de possíveis fraudes e, ainda, regulando a relação entre auditor e cliente.

Por fim, a auditoria é entendida como uma atividade em que a confiança e expertise na relação cliente e auditor é conquistada de maneira gradual e lenta. Com isso, Carcello e Neal (2003) afirmam que as relações das firmas de auditorias com seus clientes tendem a ser de longo prazo, objetivando buscar essa confiança e expertise nas demonstrações financeiras da companhia auditada.

Em síntese, a relação entre auditor e cliente envolve, de certa forma, algum grau de conflito de interesse, na medida em que o cliente contrata e remunera o auditor, mas o trabalho desse atende, em última instância, aos interesses dos usuários externos. Nesse sentido, o estabelecimento de mecanismos que assegurem a independência dos auditores e a verificação da efetividade desses mecanismos assumem particular relevância.

\subsection{As Consequências da Opinião do Auditor}

As consequências da emissão de uma opinião modificada e o reflexo na relação auditorcliente é uma questão que vem gerando debates e questionamentos no mercado de capitais, notadamente quanto a se e de que forma o auditor pode ser influenciado pela companhia auditada e qual seria o tipo de influência sofrida por esse profissional. Sobre essas questões, Francis e Wilson (1988) encontraram evidências de que as empresas de maior porte financeiro tendem a demitir menos auditores e procuram "negociar" o relatório devido ao alto preço pago pelo serviço, temendo os altos custos que podem incorrer em caso de opinião modificada.

Carcello e Neal (2003), por sua vez, não encontraram tais achados em sua pesquisa. Eles obtiveram evidências de que as empresas tendem a manter uma parceria de longa duração com seus auditores, para poder aperfeiçoar seus controles e gerar confiança aos seus investidores com a manutenção de uma mesma firma, fato que corrobora a conclusão dos autores de que um trabalho de longo prazo tende a diminuir a incidência da demissão do auditor. Haskins e Willians (1990), por sua vez, tinham constatado que as empresas buscam evitar a demissão de auditores que têm ampla experiência no seu ramo de negócios temendo uma reação negativa dos investidores.

Os resultados da pesquisa de Carcello e Neal (2003) constatam, também, que nos casos em que há demissão de auditores, a maioria dos membros do Comitê de Auditoria, responsáveis pela demissão, são vinculados de alguma maneira à administração, têm ações da companhia e têm menos experiência em gestão corporativa. Logo, nota-se que quanto mais independente e quanto mais expertise em governança tiver o Comitê de Auditoria, menor será a chance de o auditor sofrer uma retaliação pela emissão de relatório com modificação de opinião.

Hennes, Leone e Miller (2008) afirmam que uma das consequências da emissão, pelo auditor, de relatório com ressalvas é a demissão do Chief Executive Officer (CEO) ou do Chief 
Financial Officer (CFO) e que o board da empresa pode ter incentivos para demitir o auditor após a revelação de uma fraude, se eles acreditarem que a mudança de auditor vier a restaurar a credibilidade da empresa. Por outro lado, eles podem manter a firma de auditoria se acreditarem que esse auditor é capaz de encontrar outros erros. Se o Conselho considerar o aumento da dificuldade dos auditores em enfrentar detecção dessas irregularidades, espera-se demissões a uma taxa mais elevada para reformulações causadas por erros do que em comparação com aqueles causados por irregularidades.

Assim como Carcello e Neal (2003), Hennes, Leone e Miller (2013) constataram que as consequências da emissão de um relatório "modificado" vêm crescendo substancialmente ao longo dos anos. Com o objetivo de verificar se existem evidências que comprovem a demissão do auditor devido a reafirmações sobre as demonstrações contábeis, os autores encontraram dados que comprovam que os auditores são demitidos numa taxa maior do que o normal após as republicações. As republicações (restatements) são definidas como a revisão e publicação de afirmações anteriores de uma companhia a respeito de sua situação patrimonial e financeira, posteriormente, em decorrência de erros materiais significativos.

Em outro teste de hipótese, Hennes, Leone e Miller (2013) analisaram a taxa de demissão dos auditores, de acordo com as suas características, constatando que as empresas que contratam as big four necessitam de um maior apoio, devido à complexidade das suas operações, e pagam mais caro por isso. Nesses casos, uma troca ou demissão do auditor custaria caro para essas empresas, o que aumentaria a tendência de se manter a relação já existente. Já as empresas menores tendem a atender clientes de menor porte e ter uma maior taxa de demissão, devido ao baixo custo da troca.

Por fim, Hennes, Leone e Miller (2013) pesquisaram a resposta/reação do mercado ao anúncio da demissão dos auditores, constatando reação positiva e negativa diante da demissão. A reação negativa foi verificada quando o auditor pede demissão ou a mudança do auditor é devida a discordâncias com a administração da empresa. A reação positiva, por sua vez, ocorre quando a substituição do auditor decorre da constatação de uma irregularidade e a mudança de auditoria foi de uma empresa de menor porte para outra de maior porte, visando a possível identificação de erros.

Estudos anteriores têm argumentado que a reação do mercado à demissão é negativa porque a interrupção da prestação do serviço, para eles, significa que a empresa estava tentando influenciar o auditor (CHOW; RICE, 1982; SCHWARTZ; MENON, 1985).

Teoh (1992) obteve resultados que sugerem que o auditor será relutante em modificar uma opinião devido a uma possível demissão, mas que isso não é uma regra e pode haver exceções. Em contrapartida, foi observado que a existência de custos indiretos na emissão de uma opinião modificada desencoraja o auditor a emitir opiniões modificadas.

Foi encontrado ainda, no estudo de Teoh (1992), que as reações dos investidores às mudanças das empresas de auditoria estão condicionadas à opinião dos auditores em relação às demonstrações financeiras da empresa e outros fatores relacionados aos custos benefícios que essa mudança trará para a entidade. Por fim, esse mesmo artigo afirma que as trocas de auditoria dependem, em parte, do valor da companhia. As empresas de valor intermediário de mercado mudam de auditor na esperança de conseguirem opiniões favoráveis, enquanto as de baixo valor não mudam de auditor por não há esperança de mudança de opinião. As empresas de grande porte, por sua vez, são indiferentes à mudança, pois esperam, de maneira confiável, um relatório "limpo" do auditor.

Como se percebe, pesquisas sobre as consequências, para o auditor, da emissão de relatório com opinião modificada têm sido objeto de discussão na literatura internacional, mas não foi encontrada pesquisa em âmbito nacional sobre o tema. 


\subsection{Relação entre Governança Corporativa e Auditoria}

De acordo com o Instituto Brasileiro de Governança Corporativa [IBCG] (2009), a transparência e a prestação de contas estão entre os princípios de governança corporativa. Nesse sentido, o trabalho do auditor vem de encontro aos princípios da governança corporativa, uma vez que a auditoria busca atestar a veracidade das informações contábeis e financeiras divulgadas pela empresa (Dantas, 2012).

Considerando os propósitos do trabalho do auditor e a afirmação de Murcia, Borba e Schiehll (2008) de que pode ocorrer conflito de interesse entre auditor e cliente, o que significa afirmar que a independência do auditor é fundamental para um trabalho de auditoria com confiabilidade. Moraes e Martinez (2014) corroboram o entendimento de que a independência da equipe de auditoria possibilita que o trabalho desenvolvido por esses profissionais seja considerado como um dos mecanismos de governança corporativa. É natural supor, portanto, que a adoção do modelo de governança corporativa é importante para propiciar um ambiente adequado para o auditor realizar seu trabalho.

Abbott e Parker (2000), por sua vez, afirmam que as empresas com alto nível de governança corporativa tendem a contratar serviços de maior qualidade. Nesse sentido esperase que a empresa esteja interessada única e exclusivamente na qualidade da auditoria, independente do relatório divulgado e da emissão de opinião desfavorável à empresa (opinião com ressalva, adversa ou abstenção), garantindo a independência do auditor, preocupando-se somente com a credibilidade que o auditor transmite aos usuários das informações. Ainda sobre a qualidade de auditoria e adoção de práticas de governança corporativa, Dantas e Medeiros (2015) testaram e confirmaram a hipótese de que a presença de um Comitê de Auditoria na empresa (um dos mecanismos de governança corporativa) tende a aumentar a qualidade da auditoria realizada pelos auditores independentes, pois, é esperado que esse comitê crie condições para aplicação do ceticismo profissional do auditor.

Considerando esses pressupostos, é natural se esperar que companhias com maior nível de governança corporativa assegurem maior grau de independência aos auditores, o que pode fazer com que os auditores dessas companhias estejam menos expostos a eventuais penalizações - como a descontinuidade contratual - nos casos de emissão de relatório com opinião modificada.

\subsection{O Rodízio de Firmas de Auditoria}

Uma vez que se busca, nessa pesquisa, constatar se a emissão de opinião modificada pode resultar em descontinuidade do contrato da firma de auditoria com o cliente auditado fazse necessário verificar se a troca foi compulsória ou não. Essa troca pode vir a ser obrigatória devido à política de rodízio de firmas de auditoria adotada pela CVM.

O rodízio foi inicialmente adotado no ano de 1999, seguindo as normas da Instrução da $\mathrm{CVM} \mathrm{n}^{\mathrm{o}}$ 308, de 14 de maio de 1999. Em seguida, foi emitida a Deliberação CVM n ${ }^{\circ}$ 549, de 10 de setembro de 2008, posteriormente alterada pela Deliberação CVM n ${ }^{\circ}$ 699, de 21 de setembro de 2011, que suspendeu a obrigatoriedade do rodízio entre 2008 e 2011 - período julgado relevante para a consolidação dos novos padrões contábeis, aderentes aos padrões emitidos pelo IASB. Se entendeu importante não impor a troca de auditores em um momento de profunda transformação dos padrões contábeis.

A última alteração ocorreu por meio da Instrução CVM no 509 , de 16 de novembro de 2011, a qual estabeleceu que as companhias que instalarem e mantiverem Comitê de Auditoria, nas condições exigidas pela Instrução, poderão manter o mesmo auditor independente para a prestação de serviços por até dez anos consecutivos. Como a criação e permanência desse 
Comitê é facultativa, as empresas que optarem por não adotá-la devem manter as rotações do auditor independente a cada cinco anos.

Assim, considerando que há a possibilidade de uma eventual troca de auditoria na sequência à emissão de relatório de opinião modificado, ser determinado não pelo tipo de relatório e sim pela imposição do rodízio obrigatório, é importante que essa possibilidade seja considerada nos testes empíricos sob pena de comprometimento dos resultados apurados.

\section{Procedimentos Metodológicos}

O presente estudo caracteriza-se como empírico, por atender às características definidas por Martins (2000), uma vez que são utilizadas técnicas para coleta e tratamento de dados que privilegiam estudos práticos e tendo preocupação com um tipo de relação que, no caso, é se existe relação entre a emissão de relatório de auditoria com opinião modificada e a demissão do auditor.

\subsection{Hipóteses de Pesquisa}

Tendo em vista os objetivos da pesquisa, são levantadas algumas hipóteses, baseadas nos fundamentos teóricos da Seção 2, para compreender se um relatório com modificação de opinião pode vir a se configurar em um risco para as firmas de auditoria em relação à continuidade do contrato com o cliente.

A primeira hipótese tem por base alguns dos estudos abordados nas seções 2.2 e 2.3 . Zagonov (2011), por exemplo, destaca que ao longo do trabalho de auditoria, aumentam as preocupações a respeito de uma possível influência da administração sobre o auditor independente. Francis e Wilson (1988) observaram em seus testes que empresas de grande porte buscam "negociar" os relatórios de auditoria. Esses autores apontam uma preocupação com as consequências da emissão de uma opinião modificada, que pode levar à troca ou demissão do auditor responsável. Hennes, Leone e Miller (2008) foram além do simples questionamento, e encontraram indícios de que essa opinião modificada pode gerar a demissão do auditor, caso a diretoria da empresa auditada não concorde com tal opinião. Assim, com base nesses estudos, formula-se a seguinte hipótese de pesquisa, a ser testada empiricamente:

$\boldsymbol{H}_{1}:$ No âmbito do mercado de capitais brasileiro, a emissão de relatório de auditoria com opinião modificada aumenta a probabilidade de descontinuidade do contrato entre auditor e cliente.

A segunda hipótese parte dos argumentos expostos por Hennes, Leone e Miller (2013), que encontraram evidências de que as empresas que contratam as firmas de auditoria do grupo big four buscam auditores com expertise, devido à alta complexidade dos seus negócios, e que uma eventual troca dos auditores independentes acarretaria em altos custos para essas empresas. Com base nesses preceitos, e considerando os fundamentos expostos em $\boldsymbol{H}_{l}$, é formulada a seguinte hipótese:

$\boldsymbol{H}_{2}$ : No âmbito do mercado de capitais brasileiro, as firmas de auditoria de grande porte, as big four, registram menor probabilidade, do que as demais, de descontinuidade do contrato entre auditor e cliente, quando emitem relatório com opinião modificada.

A terceira hipótese associa o trabalho de auditoria à estrutura de governança corporativa da empresa cliente. Uma vez que, conforme Moraes e Martinez (2014), a realização de uma auditoria, de maneira independente, sem influências de terceiros, é entendida como um dos mecanismos do modelo de governança corporativa, espera-se que as empresas que adotam esse padrão de gestão tendam a proteger a independência dos auditores mais eficazmente, assegurando a possibilidade desses profissionais opinarem livremente sobre as demonstrações, 
sem o risco de penalizações. Assim, associando essa premissa aos fundamentos destacados em $\boldsymbol{H}_{1}$, é formulada a seguinte hipótese de pesquisa:

$\boldsymbol{H}_{3}$ : No âmbito do mercado de capitais brasileiro, as empresas que adotam práticas de governança corporativa reconhecidas, registram menor probabilidade, do que as demais, de descontinuidade do contrato com os auditores independentes, quando esses emitem relatório com opinião modificada.

\subsection{Definição dos Modelos}

Para testar as hipóteses de pesquisas são analisadas as estatísticas descritivas das variáveis de interesse, além das estimações dos modelos (3.1) e (3.2), por dados em painel, com efeitos fixos nos períodos.

$$
\begin{gathered}
T A_{i, t}=\beta_{0}+\beta_{t}+\beta_{1} \operatorname{Mod}_{i, t-1}+\beta_{2}\left(\operatorname{Mod}_{i, t-1} * B 4_{i, t-1}\right)+\beta_{3}\left(\operatorname{Mod}_{i, t-1} * G C_{i, t-1}\right)+\varepsilon_{i, t} \\
\left(T A^{*} T A_{V}\right)_{i, t}=\beta_{0}+\beta_{t}+\beta_{1} \operatorname{Mod}_{i, t-1}+\beta_{2}\left(\operatorname{Mod}_{i, t-1} * B 4_{i, t-1}\right)+\beta_{3}\left(\operatorname{Mod}_{i, t-1} * G C_{i, t-1}\right)+\varepsilon_{i, t}
\end{gathered}
$$

Onde:

$T A_{i, t}$ : $\quad$ variável dummy, assumindo 1 para os casos em que houve troca dos auditores independentes por parte da empresa $\boldsymbol{i}$, no período $\boldsymbol{t}$, e 0 para os demais;

$T A v_{i, t}$ : $\quad$ variável dummy, assumindo 1 para os casos em que a empresa $\boldsymbol{i}$ trocou os auditores independentes de forma voluntária, sem a imposição do rodízio obrigatório, no período $t$ e 0 para os demais;

$\operatorname{Mod}_{i, t-1}$ : variável dummy, assumindo 1 para os casos em que as demonstrações financeiras da empresa $\boldsymbol{i}$, no período $\boldsymbol{t}$-1, foram objeto de opinião modificada por parte dos auditores independentes e 0 para os demais;

$B 4_{i, t-1}$ : variável dummy, assumindo 1 para os casos em que a empresa $\boldsymbol{i}$ foi auditada por uma das empresas de auditoria que consta no chamado grupo big four - PWC, KPMG, E\&Y ou Deloitte - no período t-1, e 0 para os demais;

$G C_{i, t-1}$ : variável dummy, assumindo 1 para os casos em que a empresa $\boldsymbol{i}$ adota um dos segmentos de governança corporativa listados pela BM\&FBovespa, no período $\boldsymbol{t}-1$, e 0 para os demais.

Os modelos (3.1) e (3.2) se diferenciam exclusivamente pela definição das variáveis dependentes. O primeiro considera todos os eventos de troca de auditoria, independentemente de ter sofrido ou não os efeitos do rodízio obrigatório imposto pelo regulador. No segundo, são isolados apenas os casos em que a troca se deu de forma voluntária. O propósito dos dois modelos é controlar se os eventuais efeitos de descontinuidade da relação contratual auditor/cliente nos casos de emissão de relatório com opinião modificada não são explicadas pelas condições impostas pelo rodízio obrigatório.

Para a realização dos testes, os modelos (3.1) e (3.2) são aplicados em etapas inicialmente considerando apenas a variável representativa da modificação de opinião (Mod), e depois incorporando as variáveis associadas às firmas de auditoria big four $(\boldsymbol{B} 4)$ e à adoção de modelos de governança corporativa $(\boldsymbol{G C})$. Embora o registro em um dos níveis de governança corporativa da BM\&FBovespa não signifique, necessariamente, que as entidades adotam práticas de governança corporativa apropriadas, são utilizadas neste estudo como proxy de tal condição, na ausência de outro critério mais objetivo. As estimações com o uso de dados em painel com efeitos fixos nos períodos se justificam pela possibilidade de controlar a heterogeneidade temporal existente nas séries (Baltagi, 2008).

Quanto à análise das hipóteses de pesquisa, Mod é a variável independente de interesse para testar $\boldsymbol{H}_{1}$. A confirmação da hipótese está condicionada à constatação de relação positiva e estatisticamente relevante com a variável dependente. Para concluir sobre $\boldsymbol{H}_{2}$ é considerada a variável de interação entre $\boldsymbol{M o d}$ e $\boldsymbol{B} 4$ - a hipótese é corroborada se apresentarem sinal negativo 
e relevância estatística. Por fim, a corroboração de $\boldsymbol{H}_{3}$ depende da constatação de sinal negativo e relevância estatística para a variável de interação entre $\boldsymbol{M o d}$ e $\boldsymbol{G C}$. Em todas essas relações, cabe ressaltar que a variável dependente é contemporânea e as variáveis independentes são defasadas, de forma a identificar se a troca de auditoria, no momento $\boldsymbol{t}$, é influenciada pelo comportamento das variáveis independentes no período anterior $(\boldsymbol{t}-\mathbf{1})$.

\subsection{Amostra e Fonte de Dados}

Para a realização dos testes empíricos - aplicação dos modelos (3.1) e (3.2) - foram selecionadas, inicialmente, 392 empresas não financeiras listadas na BM\&FBovespa. Dentre essas, 54 não foram consideradas na amostra devido a não apresentarem informações suficientes para análise dos dados. Assim, a pesquisa abrangeu os relatórios dos auditores independentes sobre as demonstrações financeiras anuais de 338 companhias, considerando o período de 2009 a 2015.

Ressalta-se que não foram utilizadas na amostra as instituições financeiras devido à não exigência do rodízio de firmas de auditoria. A Resolução n ${ }^{\circ} 3.606$, de 11 de setembro de 2008, do Conselho Monetário Nacional (CMN), estabeleceu que, para as instituições supervisionadas pelo Banco Central do Brasil, apenas os responsáveis técnicos deveriam ser substituídos a cada 5 anos. Logo, percebe-se que essas poderiam vir a contaminar a amostra.

As demonstrações financeiras foram obtidas diretamente no sítio da CVM na internet, cabendo ressaltar que para algumas das empresas da amostra não foram encontrados relatórios para os seis exercícios pesquisados. Nesse caso, foram considerados apenas aqueles disponíveis.

Para a identificação sobre se a troca de auditoria ocorreu voluntariamente ou em função dos requisitos do rodízio obrigatório, foram consultadas as informações a respeito que constam no Relatório de Referência das empresas, também disponível no sítio da CVM na internet.

\section{Análise dos Resultados}

Considerando que o presente estudo teve como objetivo principal identificar se existe consequência na relação contratual entre a empresa e o auditor devido a emissão de relatório de auditoria com opinião modificada, e se características como o fato de a firma de auditoria ser uma big four ou a empresa auditada pertencer a um dos segmentos de governança corporativa da BM\&FBovespa afetam essa relação causa-efeito, foram apuradas as variáveis necessárias para a estimação dos modelos (3.1) e (3.2), tendo por base a amostra definida na Seção 3.3.

\subsection{Estatísticas Gerais}

A primeira etapa dos testes consistiu em analisar os relatórios de auditoria sobre as demonstrações financeiras das 338 companhias da amostra, considerando o período de 2009 a 2015. Na Tabela 1 são consolidadas as estatísticas gerais desse mapeamento inicial do estudo.

A análise dos 2.239 relatórios de auditoria revela, em relação ao tipo de opinião emitida pelos auditores independentes, que a expressiva maioria das demonstrações financeiras $(91,6 \%)$ recebeu opinião não modificada - relatório sem ressalvas. Foram encontrados 188 relatórios (8,4\% da amostra) com opinião modificada - relatórios com ressalvas ou com abstenção de opinião. Não foi identificado nenhum relatório com opinião adversa, que representa um dos mais altos graus de discordância do auditor, junto com a abstenção de opinião. O relatório com opinião adversa é emitido quando há evidências suficientes para a fundamentação de opinião que levam a concluir que as distorções detectadas pelos auditores são materiais e generalizadas. 
$\mathrm{Na}$ abstenção de opinião, o auditor foi impossibilitado de conseguir aplicar os procedimentos necessários à obtenção de evidências apropriadas e suficientes para formar sua opinião.

Tabela 1: Estatísticas gerais sobre os relatórios de auditoria analisados

\begin{tabular}{|c|c|c|}
\hline Descrição & Quant. & Perc. \\
\hline Total de relatórios & 2.239 & $100.0 \%$ \\
\hline Sem ressalva & 2.051 & $91.6 \%$ \\
\hline Com ressalva & 150 & $6.7 \%$ \\
\hline Abstenção de opinião & 38 & $1.7 \%$ \\
\hline Opinião adversa & 0 & $0.0 \%$ \\
\hline Demonstrações auditadas por big four & 1.624 & $72.5 \%$ \\
\hline Demonstrações de empresas GC & 1.236 & $55.2 \%$ \\
\hline Trocas de auditoria & 451 & $20.1 \%$ \\
\hline Trocas voluntárias & 223 & $49.4 \%$ \\
\hline Trocas obrigatórios (rodízio) & 228 & $50,6 \%$ \\
\hline
\end{tabular}

Sobre as características de quem auditou e de quem é auditado, foi constatado que $55,2 \%$ das demonstrações examinadas foram preparadas por empresas que participam de algum tipo de segmento especial de listagem da BM\&FBovespa - Bovespa Mais, Bovespa Mais Nível 2, Novo Mercado, Nível 2 ou Nível 1 - esses segmentos especiais prezam por mecanismos de governança corporativa, e para a empresa ser listada em um desses segmentos ela deve adotar, voluntariamente, práticas de governança corporativa. Esses dados evidenciam que boa parte das companhias brasileiras já integram um dos segmentos de corporativa. Ressalta-se que não é objeto dessa pesquisa evidenciar e dissertar a respeito da diferenciação desses segmentos e seus níveis de prática de governança

Outra característica também encontrada foi que $72,5 \%$ dos relatórios analisados foram emitidos por uma das maiores firmas de auditoria, as big four. Percebe-se, então, que há predominância dos auditores de maior porte no mercado de capitais brasileiro.

No que se refere aos casos de trocas de auditoria, que são consideradas como a mudança da firma de auditoria de um ano para outro, foram identificadas 451 trocas, o que corresponde a $20,1 \%$ do total dos relatórios de auditoria analisados. Desses $20,1 \%$, ligeira maioria $(50,6 \%)$ foram de trocas de auditorias voluntárias e o restante $(49,4 \%)$ são referentes a trocas em decorrência do rodízio obrigatório. Esses são os casos de interesse no presente estudo, que caracterizam as variáveis dependentes dos modelos (3.1) e (3.2).

\subsection{Estimação do Modelo e Teste das Hipóteses}

Preliminarmente à estimação do modelo (3.1), para se prevenir do risco de multicolinearidade, foi elaborada matriz de correlação entre as variáveis independentes, para identificar se há alto grau de correlação entre pares de regressores. Adotando-se a regra básica sugerida por Gujarati (2006), de que a multicolinearidade é um problema sério quando a correlação entre as variáveis independentes é maior que 0,8 , os resultados demonstrados na Tabela 2 eliminam esse risco.

Eliminado o risco de multicolinearidade e considerando que o fato de todas variáveis do modelo serem do tipo dicotômica - não havendo, portanto, o risco de estacionariedade das séries - o passo seguinte consistiu na estimação do modelo de referência. 
Tabela 2: Matriz de correlação de Pearson entre os regressores dos modelos (3.1) e (3.2)

\begin{tabular}{cccc}
\hline & $\boldsymbol{M o d}$ & $\boldsymbol{M o d}^{*} \boldsymbol{B} 4$ & $\boldsymbol{M o d}^{*} \boldsymbol{G C}$ \\
\hline $\boldsymbol{M o d}$ & 1.0000 & & \\
$\boldsymbol{M o d}^{*} \boldsymbol{B} 4$ & 0.5653 & 1.0000 & \\
$\boldsymbol{M o d}^{*} \boldsymbol{G C}$ & 0.4837 & 0.5085 & 1.0000 \\
\hline
\end{tabular}

Onde: Mod é a variável dummy assumindo 1 para os casos em que as demonstrações financeiras foram objeto de opinião modificada por parte dos auditores independentes e 0 para os demais; B4 é a variável dummy assumindo 1 para os casos em que a empresa foi auditada por uma das chamadas big four e 0 para os demais; $\boldsymbol{G C}$ é a variável dummy assumindo 1 para os casos em que a empresa adota um dos segmentos de governança corporativa listados pela BM\&FBovespa e 0 para os demais.

Para os testes das hipóteses de pesquisa foram realizadas estimações de derivações dos modelos (3.1) e (3.2) - com e sem a consideração dos efeitos das variáveis $\boldsymbol{B} 4$ e $\boldsymbol{G C}$ - com o uso de dados em painel com efeitos fixos nos períodos, utilizando o método de covariância $S U R$ (PCSE) período, que gera parâmetros robustos mesmo na presença de heterocedasticidade e autocorrelação nos resíduos. Os resultados são consolidados na Tabela 3.

Tabela 3: Estimação dos modelos (3.1) e (3.2), para identificação da relação entre a emissão de opinião modificada e a troca da firma de auditoria

\begin{tabular}{|c|c|c|c|c|}
\hline \multicolumn{5}{|c|}{ Modelos Testados: } \\
\hline $\begin{array}{r}T A_{i, t}=\beta_{0} \\
\left(T A^{*} T A_{V}\right)_{i, t}=\rho\end{array}$ & $\begin{array}{l}{ }_{1} \operatorname{Mod}_{i, t-1} \\
+\beta_{1} \operatorname{Mod}_{i, t}\end{array}$ & $\begin{array}{l}d_{i, t-1} * B \\
\operatorname{Mod}_{i, t-1} *\end{array}$ & $\begin{array}{l}\beta_{3}\left(\operatorname{Mod}_{i, t-}\right. \\
+\beta_{3}(\operatorname{Mod}\end{array}$ & $\begin{array}{l}(, t-1)+\varepsilon_{i, t} \\
\left.C_{i, t-1}\right)+\varepsilon_{i, t}\end{array}$ \\
\hline $\begin{array}{c}\text { Variável } \\
\text { Dependente }\end{array}$ & $\boldsymbol{T A}$ & $\boldsymbol{T} \boldsymbol{A}$ & $T A * T A v$ & $T A * T A v$ \\
\hline $\boldsymbol{C}$ & $\begin{array}{l}0,2273 \\
(0,0000) \\
* * *\end{array}$ & $\begin{array}{c}0,2273 \\
(0,0000) \\
* * *\end{array}$ & $\begin{array}{c}0,1074 \\
(0,0000) \\
* * *\end{array}$ & $\begin{array}{c}0,1074 \\
(0,0000) \\
* * *\end{array}$ \\
\hline $\operatorname{Mod}(-1)$ & $\begin{array}{c}0,1013 \\
(0,0006) \\
* * *\end{array}$ & $\begin{array}{c}0,0968 \\
(0,0073) \\
* * *\end{array}$ & $\begin{array}{c}0,0997 \\
(0,0004) \\
* * *\end{array}$ & $\begin{array}{c}0,0686 \\
(0,0474) \\
* *\end{array}$ \\
\hline $\operatorname{Mod} * B 4(-1)$ & & $\begin{array}{l}-0,0740 \\
(0,2602)\end{array}$ & & $\begin{array}{c}0,0342 \\
(0,5671)\end{array}$ \\
\hline $\operatorname{Mod} * G C(-1)$ & & $\begin{array}{c}0,1288 \\
(0,0705) \\
*\end{array}$ & & $\begin{array}{c}0,0981 \\
(0,1438)\end{array}$ \\
\hline $\mathrm{N}^{\mathrm{o}}$ de Entidades & 338 & 338 & 338 & 338 \\
\hline $\mathrm{N}^{\mathrm{o}}$ de Observações & 1901 & 1901 & 1901 & 1901 \\
\hline Período & $2009 / 2015$ & $2009 / 2015$ & $2009 / 2015$ & $2009 / 2015$ \\
\hline $\mathrm{R}^{2}$ & 0,0981 & 0,0994 & 0,0176 & 0,0193 \\
\hline $\mathrm{R}^{2}$ ajustado & 0,0952 & 0,0956 & 0,0145 & 0,0151 \\
\hline Estatística-F & 34,3180 & 26,0967 & 5,6671 & 4,6464 \\
\hline $\mathrm{F}$ (p-valor) & 0,0000 & 0,0000 & 0,0000 & 0,0000 \\
\hline
\end{tabular}

Onde: $\boldsymbol{T A}$ é a variável dummy assumindo 1 para os casos em que houve troca dos auditores independentes por parte da empresa $\boldsymbol{i}$, no período $\boldsymbol{t}$, e 0 para os demais; $\boldsymbol{T} \boldsymbol{A} \boldsymbol{v}$ é a variável dummy assumindo 1 para os casos em que a empresa $i$ trocou os auditores independentes, sem a imposição do rodízio obrigatório, no período t, e 0 para os demais; Mod é a variável dummy assumindo 1 para os casos em que as demonstrações financeiras da empresa $\boldsymbol{i}$ no período $\boldsymbol{t}$-1, foram objeto de opinião modificada por parte dos auditores independentes, e 0 para os demais; $\boldsymbol{B} 4$ é a variável dummy assumindo 1 para os casos em que a empresa $\boldsymbol{i}$ foi auditada por uma das empresas de auditoria que consta no chamado grupo big four no período $\boldsymbol{t}-\mathbf{1}$, e 0 para os demais; $\boldsymbol{G C}$ é a variável dummy assumindo 1 para os casos em que a empresa $\boldsymbol{i}$ adota um dos segmentos de governança corporativa listados pela BM\&FBovespa, no período $\boldsymbol{t}-\mathbf{1}$, e 0 para os demais. Nível de Significância: *** 1\%;** 5\%;*10\%. P-valores entre parênteses 
Os resultados dos testes empíricos evidenciados na Tabela 3, nas quatro estimações, revelam que há associação positiva e estaticamente relevante entre as variáveis dependentes $(\boldsymbol{T} \boldsymbol{A}$ ou a variável de interação $\boldsymbol{T} \boldsymbol{A} * \boldsymbol{T} \boldsymbol{A} \boldsymbol{v})$ e a variável independente de interesse $(\boldsymbol{M o d})$ defasada em um período. Isso evidencia que há relação positiva e estatisticamente relevante entre a emissão de uma opinião modifica em um período e a substituição dos auditores independentes no momento seguinte. Isso ocorre tanto em relação ao conjunto das trocas de auditoria quanto ao se considerar apenas os casos de trocas voluntárias - excluindo os casos de trocas decorrentes de rodízios obrigatórios, impostos pela CVM.

Esses resultados corroboram as expectativas da hipótese $\boldsymbol{H}_{\boldsymbol{l}}$, no sentido de que a emissão de opinião modificada por parte do auditor tem consequências para a continuidade da relação contratual auditor-cliente. Esses achados são coerentes com as evidências encontradas por Hennes, Leone e Miller (2013) a respeito de uma maior taxa de demissão dos auditores em situações do gênero.

Constatada a relação entre a emissão de relatório com modificação de opinião e a demissão do auditor, o passo seguinte consistiu em verificar se essa relação é impactada pelo fato de a firma de auditoria ser uma das big four, aprofundando o objetivo da pesquisa. Os testes da estimação dos modelos (3.1) e (3.2) com a consideração dos efeitos da variável de interação $\left(\boldsymbol{M o d}^{*} \boldsymbol{B} 4\right)$ revelam que a relação dessa com as variáveis dependentes - representativas do conjunto das trocas de auditoria ou apenas as trocas voluntárias, excluindo as decorrentes do rodízio obrigatório - não apresentou relevância estatística.

Assim, não obstante as evidências de Hennes, Leone e Miller (2013), no sentido de que as empresas tendem a evitar a troca de auditoria quando essa é uma das big four, os resultados evidenciam que não há diferença estatisticamente relevante entre a emissão de opinião modificada por uma big four ou não big four em um período e a descontinuidade da relação contratual auditor-cliente no período seguinte. Com isso, a hipótese $\boldsymbol{H}_{2}$ não é corroborada, tendo em vista que essa previa que as big four registrariam menor probabilidade de descontinuidade do contrato com o cliente, quando emitisse opinião modificada, o que não foi confirmado. Isso ocorre independentemente de se considerar o conjunto das trocas de auditoria ou apenas as trocas não associadas ao rodízio obrigatório.

A terceira etapa consiste em testar outra peculiaridade referente à emissão de opinião modificada. Teriam os auditores independentes menor risco de demissão caso a empresa auditada integrasse o rol de entidades que adotam níveis de governança corporativa reconhecidos pelo mercado? Essa pergunta é o que dá base à formulação da hipótese $\boldsymbol{H}_{3}$. Os resultados encontrados no modelo (3.1) - variável dependente considerando o conjunto de todas as trocas de auditoria da amostra - demonstram uma associação positiva com baixa relevância estatística (p-valor de 0,0705 ) entre a troca de auditoria e o fato de no período anterior a empresa que faz parte dos níveis de governança corporativa da BM\&FBovespa ter recebido opinião modificada sobre suas demonstrações financeiras. Ao se restringir os casos de troca de auditoria aos eventos voluntários - excluindo os rodízios obrigatórios - não foi constatada relação estatisticamente relevante com a variável independente representativa de opinião modificada sobre demonstrações financeiras de empresa que faz parte dos níveis de governança corporativa da BM\&FBovespa $(\boldsymbol{M o d} * \boldsymbol{G C})$.

A combinação desses resultados permite refutar a hipótese de pesquisa $\boldsymbol{H}_{3}$, ou seja, a melhor estrutura de governança corporativa da empresa auditoria não é capaz de reduzir a probabilidade de demissão do auditor, nos casos de emissão de opinião modificada a respeito das demonstrações financeiras. Embora com foco distinto, esse resultado vai de encontro às evidências sugeridas no estudo de Dantas e Medeiros (2014), que confirmaram em sua pesquisa que o fato da empresa adotar um mecanismo de governança corporativa (no caso, o Comitê de 
Auditoria) aumenta a qualidade da auditoria desenvolvida, uma vez que os auditores teriam maior liberdade e condições para aplicar o ceticismo profissional.

Em resumo, os testes demonstram que há relação entre a interrupção da relação auditorcliente e o fato de, no período anterior, o auditor ter emitido relatório com opinião modificada sobre as demonstrações financeiras. Foi constatado, adicionalmente, que a condição de a firma de auditoria ser uma big four ou a entidade auditada pertencer aos segmentos de governança corporativa da BM\&FBovespa não reduzem a probabilidade da demissão do auditor quando da emissão de opinião modificada. Com isso, é confirmada a hipótese de pesquisa $\boldsymbol{H}_{\boldsymbol{1}}$ e refutadas $\mathrm{H}_{2}$ e $\boldsymbol{H}_{3}$.

\section{Considerações Finais}

A presente pesquisa teve como objetivo principal verificar se existe consequência para os auditores independentes, em sua relação contratual com a empresa auditada, no caso da ocorrência de emissão de relatório com opinião modificada. Foi verificado, também, se o fato da firma de auditoria ser uma big four ou a empresa auditada adotar práticas de governança corporativa reduz o risco de descontinuidade da relação contratual, mesmo com a emissão de opinião modificada.

Para testar as hipóteses apresentadas, foram analisados os relatórios de auditoria de 338 empresas de capital aberto listadas na BM\&FBovespa, compreendendo o período de 2009 a 2015, o que possibilitou a relação de testes empíricos pioneiros na literatura nacional -só foram encontrados estudos acerca do tema na literatura internacional.

Os resultados das estimações de regressões com dados em painel revelam que no âmbito do mercado de capitais brasileiro existe relação positiva entre a opinião modificada e a troca dos auditores independentes no período seguinte, confirmando a hipótese $\boldsymbol{H}_{\boldsymbol{l}}$. Logo, no Brasil a relação contratual entre empresa e firma de auditoria pode sofrer consequências em função da emissão de relatório com opinião modificada sobre as demonstrações financeiras. Essas evidências sugerem que a administração das empresas auditadas reage negativamente à emissão de opinião contrária aos seus interesses, por parte dos auditores e exercem o poder de descontinuar o contrato de prestação de serviços com esses profissionais. Outra possibilidade para esses resultados pode ser o fato de o próprio auditor se sentir mais confortável para emitir opinião modificada quando o seu contrato com o cliente já estava previsto para ser descontinuado - essa possibilidade pode ser explorada em estudos posteriores.

Adicionalmente, não foram confirmadas as hipóteses de pesquisa que previam que o fato da firma de auditoria ser uma big four ou a empresa auditada adotar práticas de governança corporativa reconhecidas pelo mercado reduziriam essa probabilidade de descontinuidade contratual entre as partes, nos casos de emissão de opinião modificada. Isso revela que: uma big four pode até registrar menor risco de rompimento contratual por parte do cliente, mas nos casos de emissão de relatório com opinião modificada não há diferença estatisticamente relevante em relação aos demais auditores; e a estrutura de governança corporativa da empresa cliente não é suficiente para aumentar a perspectiva de continuidade da relação contratual com o auditor, nos casos em que os interesses da administração são contrariados - com a emissão de opinião modificada.

De se ressaltar que os testes empíricos realizados consideraram duas formas de se estimar a variável dependente: no primeiro modelo foram considerados todos os casos de troca de auditoria, independentemente da razão da substituição do auditor; no segundo modelo foram considerados apenas os casos de troca voluntária do auditor, excluindo-se os eventos de rodízio obrigatório. O propósito foi avaliar os efeitos da opinião modificada em relação à descontinuidade contratual com e sem a condição do rodízio obrigatório. Os resultados 
confirmaram que nos dois casos o risco de demissão do auditor aumenta substancialmente. Isso pode sugerir que: (i) quando o auditor sabe que seu contrato será descontinuado em razão do rodízio obrigatório fica mais propenso a emitir opinião modificada; e (ii) quando não há rodízio obrigatório, a emissão de opinião modificada expõe o auditor ao risco de descontinuidade contratual voluntária por parte da empresa cliente.

Pioneiro na literatura nacional em relação a esse tema específico, este estudo contribui para o desenvolvimento da literatura sobre a atuação da auditoria independente, particularmente quanto à relação auditor/cliente. As evidências empíricas identificadas demonstram um quadro preocupante em relação à garantia da independência de atuação dos auditores, na medida em que a emissão de relatório com opinião modificada aumenta a probabilidade de rescisão contratual com o cliente.

O estudo tem como limitação inicial o fato de a amostra se restringir às empresas não financeiras e listadas na BM\&FBovespa, não podendo suas evidências ser estendidas a outros ambientes e grupos de entidades. Também é importante ressaltar o fato já destacado anteriormente de que o presente estudo não avalia a possibilidade de a relação entre a emissão de relatório com opinião modificada e a descontinuidade contratual ser decorrente, não da reação da administração e sim à percepção do próprio auditor de que a relação contratual já seria descontinuada.

Como sugestão de futuras pesquisas com o objetivo de verificar as consequências de uma opinião modificada, além da verificação do impacto da percepção de que o contrato seria descontinuado no tipo de relatório emitido, pode-se destacar questões como: a análise da reação do mercado à troca do auditor devido a emissão de opinião modificada; o porte e área de atuação das empresas que trocam de auditoria devido a opinião modificada; e se a emissão de uma opinião modificada pode gerar mudanças no board da empresa auditada.

\section{Referências}

ABBOTT, L. J.; PARKER, S.. Auditor selection and audit committee characteristics. Auditing: A journal of practice \& theory, v. 19, n.2, p. 47-66, 2000. DOI: 10.2308/aud.2000.19.2.47 .

AMERICAN ACCOUNTING ASSOCIATION. A statement of basic auditing concepts. The Accounting Review, v.47(supplement), n.18, 1972.

BASEL COMMITTEE ON BANKING SUPERVISION [BCBS]. The relationship between banking supervisors and banks' external auditors. BIS, January 2002. Retrieved April 15, 2015 from http://www.bis.org/publ/bcbs87.pdf.

BALTAGI, B. . Econometric analysis of panel data (Vol. 1). John Wiley \& Sons, 2008.

CARCELLO, J. V.; NEAL, T. L. Audit committee characteristics and auditor dismissals following "new" going-concern reports. The Accounting Review, v. 78, n. 1, p. 95-117, 2003. DOI: $10.2308 /$ accr.2003.78.1.95 .

CHOW, C. W.; RICE, S. J. Qualified audit opinions and auditor switching. Accounting Review, p. 326-335, 1982.

DANTAS, J. A. Auditoria em instituições financeiras: determinantes de qualidade no mercado brasileiro. Tese de Doutorado. Universidade de Brasília, Brasília, DF, 2012. 
DANTAS, J. A.; CHAVES, S. T.; SILVA, M. R.: CARVALHO, R. P. Determinações de refazimento/republicação de demonstrações financeiras pela CVM: O papel dos auditores independentes. Revista Universo Contábil, v. 7, n. 2, p. 45-64, 2011. DOI: $10.4270 /$ ruc. 2011212 .

DANTAS, J. A.; DE MEDEIROS, O. R. Determinantes de Qualidade da Auditoria Independente em Bancos. Revista Contabilidade \& Finanças, v. 26, n. 67, p. 43-56, 2015. DOI: $10.1590 / 1808-057 \times 201400030$.

DeANGELO, L.E. Auditor size and audit quality. Journal of Accounting and Economics, v. 3. p. 183-199, 1981. DOI: 10.1016/0165-4101(81)90002-1 .

FRANCIS, J. R.; WILSON, E. R. Auditor changes: A joint test of theories relating to agency costs and auditor differentiation. Accounting Review, p. 663-682, 1988.

GUJARATI, D. N. Econometria básica. 4. ed. Rio de Janeiro: Elsevier-Campus, 2006.

HASSINK, H. F.; BOLLEN, L. H.; MEUWISSEN, R. H.; DE VRIES, M. J. Corporate fraud and the audit expectations gap: A study among business managers. Journal of international accounting, auditing and taxation, v. 18, n. 2, p. 85-100, 2009. DOI: 10.1016/j.intaccaudtax.2009.05.003 .

HASKINS, M. E.; WILLIAMS, D. D. A contingent model of intra-Big 8 auditor changes. Auditing-A Journal of Practice \& Theory, v. 9, n. 3, p. 55-74, 1990.

HENNES, K. M.; LEONE, A. J.; MILLER, B. P. The importance of distinguishing errors from irregularities in restatement research: The case of restatements and $\mathrm{CEO} / \mathrm{CFO}$ turnover. The Accounting Review, v. 83, n. 6, p. 1487-1519, 2008. DOI: 10.2308/accr.2008.83.6.1487.

HENNES, K. M.; LEONE, A. J.; MILLER, B. P. Determinants and market consequences of auditor dismissals after accounting restatements. The Accounting Review, v. 89, n. 3, p. 10511082, 2013. DOI: $10.2308 /$ accr-50680 .

INTERNATIONAL ACCOUNTING STANDARDS BOARD [IASB]. Normas Internacionais de Relatório Financeiro 2011. São Paulo: Ibracon, 2015.

INSTITUTO BRASILEIRO DE GOVERNANÇA CORPORATIVA [IBGC]. Código das Melhores Práticas de Governança Corporativa. São Paulo: IBGC, 2009.

LARCKER, D.; RICHARDSON, S. Fees paid to audit firms, accrual choices, and corporate governance. Journal of Accounting Research, v. 42, n. 3, p.625-658, 2004. DOI: 10.1111/j.1475-679X.2004.t01-1-00143.x .

LONGO, C. G. Manual de Auditoria e Revisão de Demonstrações Financeiras. 2. ed. São Paulo: Atlas, 2011.

MARTINS, G. A. Manual para elaboração de monografias e dissertações. 2. ed. São Paulo: Atlas, 2000. 
MORAES, A. J.; MARTINEZ, A. L. Associação entre a remuneração dos auditores independentes e o Q de Tobin. In: Congresso USP de Controladoria e Contabilidade, 14., São Paulo, 2014. Anais ..., 2014

MURCIA, F. D. R.; BORBA, J. A.; SCHIEHLL, E. Relevância dos red flags na avaliação do risco de fraudes nas demonstrações contábeis: a percepção de auditores independentes brasileiros. Revista Universo Contábil, v. 4, n. 1, p. 25-45, 2008.

NELSON, M. W.; ELLIOTT, J.; TARPLEY, R. L. Evidence from auditors about manager's and auditor's earnings management decisions. The Accounting Review, v. 77, Suplement, p. 175-202, 2002. DOI: 10.2308/accr.2002.77.s-1.71 .

NIYAMA, J. K.; RODRIGUES, A. M. G.; RODRIGUES, J. M. Algumas reflexões sobre contabilidade criativa $\mathrm{e}$ as normas internacionais de contabilidade. Revista Universo Contábil, v. 11, n. 1, p. 69-87, 2015. DOI: 10.4270/ruc.2015104 .

NIYAMA, J. K.; SILVA, C. A. T. Teoria da Contabilidade. 3. ed. São Paulo: Atlas, 2013.

SANTOS, A. D.; GRATERON, I. R. G. Contabilidade criativa e responsabilidade dos auditores. Revista Contabilidade \& Finanças, v. 14, n. 32, p. 07-22, 2003. DOI:

10.1590/s1519-70772003000200001 .

SCHWARTZ, K. B.; MENON, K. Auditor switches by failing firms. Accounting Review, p. 248-261, 1985.

SECURITIES AND EXCHANGE COMMISSION [SEC]. Final Rule: Revision of the Commission's Auditor Independence Requirements. Release No. 33-7919. Washington, DC:

SEC, 2000. Retrieved April 02, 2015 from http:/www.sec.gov/rules/final/33-7919.htm.

TEOH, S. H. Auditor independence, dismissal threats, and the market reaction to auditor switches. Journal of Accounting Research, p. 1-23, 1992. DOI: 10.2307/2491089 .

WATTS, R. L.; ZIMMERMAN, J. L. Positive accounting theory, Englewood Cliffs, N.J. : Prentice-Hall, 1986.

WOODS, M.; HUMPHREY, C., DOWD, K.; LIU, Y. L. Crunch time for bank audits? Questions of practice and the scope for dialogue. Managerial Auditing Journal, v. 24, n. 2, p. 114-134, 2009. DOI: 10.1108/02686900910924545 .

ZAGONOV, M. Audit quality and bank risk under heterogeneous regulations. In: European Accounting Association, Annual Meeting, Rome, Italy, 34., 2011. Proceedings..., 2011.

* Artigo apresentado no XIII Congresso USP de Iniciação Científica em Contabilidade. 